\title{
Simulation de la ration ingérée par des brebis sur végétations pastorales de Crau. Approche à partir d'études de végétation
}

\author{
D Hubert, $\mathrm{P}$ Lapeyronie, G Molénat
}

INRA ENSA.M 2 Place Viala 34000 Montpellier, France

L'étude de l'ingestion de végétations pastorales par des ovins au pâturage en Crau au printemps a été faite par une lecture fine de la végétation. L'approche retenue associe la méthode des points quadrats (Daget et Poissonet, 1971, An Agr, 22, 5-41) alignés (transects) à la mesure de la hauteur maximale de chaque espèce (Heady, 1957, Ecology, 38, 313-320) en chaque point échantillonné. La végétation disparue, différence entre les mesures avant et après pâturage (pâturage en rotation avec durées de séjour courtes) constitue une image de la consommation des animaux. Cette méthode a été utilisée au printemps 1993 sur deux types de terrain de parcours de Crau : l'un non modifié, PNA (30 à $80 \%$ de Graminées, 0 à $3 \%$ de Légumineuses, 7 à $12 \%$ de Composées, 2 à $50 \%$ de végétation sèche) et l'autre amélioré par un sursemis de Trèfle souterrain associé à une fertilisation phosphatée, PAM (50 à $70 \%$ de Graminées, 12 à $20 \%$ de Légumineuses dont le Trèfle souterrain sursemé, 2 à $8 \%$ de
Composées, 2 à $30 \%$ de végétation sèche) Au cours du printemps 5 mesures ont été échelonnées: mi-mars, début avril, mi-avril, mimai et début juin.

II existe une relation linéaire $(r=0,97 ; n=$ 10) entre la biomasse disparue et la somme des hauteurs de végétation disparue; biomasse à l'entrée - refus après 4 jours de pâturage (croissance négligeable) / hauteurs entrée - hauteurs sortie. Après confirmation des mesures dans ce type de végétation il sera possible de mesurer la consommation du troupeau au moyen des observations sur la végétation in situ. II existe également une corrélation entre les contributions spécifiques à la biomasse (CSB) et les contributions spécifiques à la hauteur $(r=0,94)$; comparaison entre coupe et tri des espèces / "mesures des hauteurs". La différence entre les hauteurs des espèces avant et après pâturage fournit un estimateur de la contribution des différentes espèces à la ration.

Contributions d'espèces et groupes d'espèces à la ration ingérée (\%)

\begin{tabular}{|c|c|c|c|c|c|c|c|c|c|c|}
\hline \multirow[b]{2}{*}{ Période } & \multirow[b]{2}{*}{$\begin{array}{l}\text { mi } \\
\text { mars }\end{array}$} & \multirow[b]{2}{*}{$\begin{array}{l}\text { début } \\
\text { avril }\end{array}$} & \multicolumn{2}{|c|}{ PNA } & \multirow[b]{2}{*}{$\begin{array}{l}\text { début } \\
\text { juin }\end{array}$} & \multirow[b]{2}{*}{$\begin{array}{l}\text { mi } \\
\text { mars }\end{array}$} & \multirow[b]{2}{*}{$\begin{array}{l}\text { début } \\
\text { avril }\end{array}$} & \multicolumn{2}{|l|}{ PAM } & \multirow[b]{2}{*}{$\begin{array}{l}\text { début } \\
\text { juin }\end{array}$} \\
\hline & & & $\begin{array}{l}\text { mi } \\
\text { avril }\end{array}$ & $\begin{array}{l}\text { mi } \\
\text { mai }\end{array}$ & & & & $\begin{array}{l}\mathrm{mi} \\
\text { avril }\end{array}$ & $\begin{array}{l}\text { mi } \\
\text { mai }\end{array}$ & \\
\hline Vég.sèche & 54,4 & 28,8 & 18,6 & 3,0 & 1,8 & 36,8 & 20,3 & 2,4 & 1,0 & 0,0 \\
\hline Graminées & 41,5 & 58,9 & 69,2 & 61,4 & 84,6 & 51,6 & 58,3 & 56,5 & 60,3 & 70,4 \\
\hline Légumineuses & & 0,5 & 0,5 & 4,2 & 1,2 & 3,2 & 3,8 & 0,4 & 15,6 & 13,0 \\
\hline Trèfle sout.* & & & & & & 8,2 & 9,3 & 17,4 & 17,0 & 5,3 \\
\hline Composées & 3,7 & 8,8 & 7,5 & 25,5 & 8,2 & & 5,9 & 10,3 & 4,1 & 5,0 \\
\hline PI. diverses & 0,5 & 3,0 & 4,3 & 5,8 & 4,3 & 0,3 & 2,4 & 13,1 & 2,0 & 6,3 \\
\hline
\end{tabular}

* le Trèfle souterrain sursemé est distingué des autres Légumineuses

La forte consommation de végétation sèche élevée au début du printemps décroît régulièrement jusque début juin, La part des graminées vertes augmente ensuite dans la ration sur les deux types de parcours au cours du printemps, La pauvreté de PNA en légumineuses semble être compensée par une plus forte consommation des composées, 